\section{The gene involved in X-linked agammaglobulinaemia is a member of the src family of protein-tyrosine kinases}

\section{Vetrie et al.}

Nature 361, 226233 (1993).

IN Fig. $2 h$ of this article, the sizing of DNA fragments was incorrect. The corrected sizes are shown below, together with the appropriately amended section of the legend to Fig. 2c

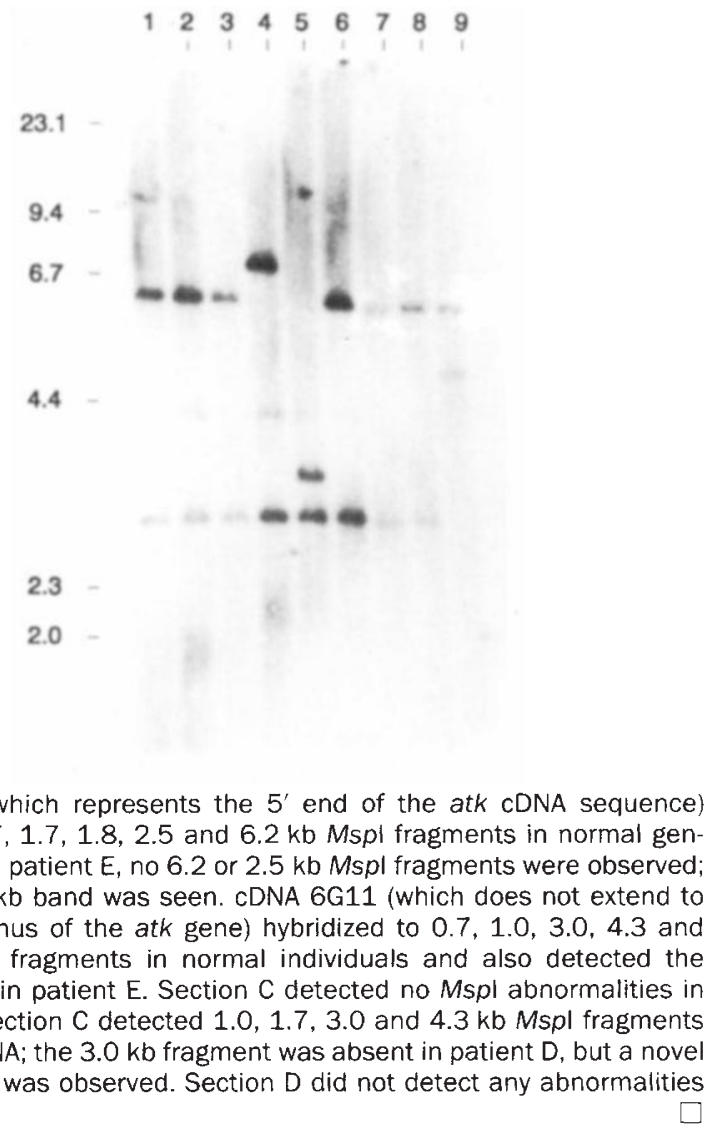

\section{Atomic structure and chemistry of human serum albumin}

\section{M. He \& D. C. Carter}

Nature 358, 209-215 (1992)

WE failed to recognize the following typographical error in the proofs of this research article. In Table 1, page 211 , the unit cell constant for the $b$ axis of the recombinant crystal form should have been $88.3 \AA$ instead of $38.3 \AA$. A statement in Fig. 4 should read that Lys 199 and His 242 are located at the 'top' of Fig. $4 a$, not the 'bottom'. In addition, we incorrectly referenced an earlier publication on recombinant albumin (ref. 25). The appropriate reference should be: Sleep, D., Belfield, G. P. \& Goodey, A. R. Biotechnology 8, 42-46 (1990).

\section{Mutations in $\mathrm{Cu} / \mathrm{Zn}$ superoxide dismutase gene are associated with familial amyotrophic lateral sclerosis}

\section{Daniel R. Rosen et al.}

Nature 362, 5962 (1993)

FIGURE 1c in this letter shows a comparison of amino-acid sequences for exon 2 of SOD-1, but incorrectly positions the residue numbers and the mutations on the sequences. The corrected panel is shown here.
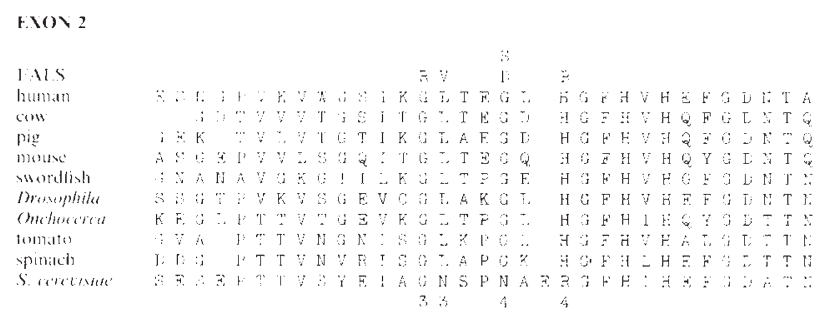

Also, in Table 3, the base-pair change for family $9967 \mathrm{C}$ should read $\mathrm{GGC} \rightarrow \mathrm{CGC}$

\section{A single amino acid of the cholecystokinin-B/gastrin receptor determines specificity for non-peptide antagonists}

\author{
Martin Beinborn*†, Young-Mee Lee*, \\ Edward W. McBride*, Suzanne M. Quinn* \\ \& Alan S. Kopin*+
}

Nature 362, 348-350 (1993)

We: have noted an error in our numbering of amino acids in this letter. The valine in transmembrane domain VI that confers antagonist affinity to the human receptor was erroneously numbered as 319 . The correct numbering should be human valine 349. In addition, the numbering of three of the canine mutants shown in Fig. 2 is incorrect: ${ }^{316} \mathrm{G}$ should be ${ }^{322} \mathrm{G} .{ }^{321} \mathrm{Y}$ should be ${ }^{327} \mathrm{Y}$, and ${ }^{360} \mathrm{SS}$ should be ${ }^{366} \mathrm{SS}$. The relative positions of the human and canine amino-acid sequences shown in Figs 2 and 4 are correct; the numbering error therefore does not affect any of our conclusions. 